\title{
Study of ethidium bromide interaction peculiarities with DNA
}

\author{
P.O. Vardevanyan ${ }^{1,3}$, A.P. Antonyan ${ }^{1}$, \\ G.A. Manukyan ${ }^{2}$ and A.T. Karapetyan ${ }^{2}$ \\ ${ }^{1}$ Biophysics Department of the Biological Faculty of Yerevan State \\ University, 375025 Yerevan, Aleck Manoogian St., 1, Armenia \\ ${ }^{2}$ Physics Department, Yerevan State University of Architecture and \\ Construction, 375009 Yerevan, Teryan St., 105, Bldg. 2. \\ ${ }^{3}$ Corresponding author: Tel, +3741-57-10-61; \\ Fax, +3741-151-874; E-mail, kensafiz@ysu.am
}

Accepted 5 October 2001

\begin{abstract}
The helix-coil transition of DNA-ethidium bromide complexes in an interval of ionic strength of $2.0 \mathrm{x}$ $10^{-3} \mathrm{M} \leq \mu_{\mathrm{Na}+} \leq 2.0 \times 10^{-2} \mathrm{M}$ has been investigated. It has been revealed that at the certain high ligandDNA ratios $\left(r_{b}\right)$ the transition interval of the complex - $(\Delta T)$ becomes equal to that of DNA itself $\left(\Delta T_{0}\right)$. It has been shown that the values of $r_{b}$ at which $\delta \Delta T=\Delta T-\Delta T_{0}=0$ depends on ionic strength of a solution. Further increasing of ligand concentration leads to its conversion from stabilizer into the destabilizer of the double-stranded DNA.
\end{abstract}

Keywords: DNA, ethidium bromide, mode of binding, bell-shape curve, melting curve

\section{Introduction}

One goal of understanding of overall affinity and specificity for interactions between nucleic acids and ligands is the study of DNA-ligand complexes (Lane A.N. and Jenkins T.C., 2000). DNA-intercalating ligands have received a great attention because this mode of binding was first used to explain the biological activity of compounds containing a planar chromophore (Chaires J.B., 1998). Antitumor cytotoxic agents with DNA-intercalative properties are characterized by the presence of a chromophore, generally tri- or tetracyclic ring system, and one or two flexible basic side chains (Antonini I. et al., 1997). On the other hand the definition of stabilizing and destabilizing effects of such kinds of ligands makes possible finding-out of mechanisms underlying the peculiarities of DNA functioning (Karapetian A.T., 1991). From this point of view it is interesting ethidium bromide $(\mathrm{EtBr})$, which is a stabilizer of double-stranded (ds) DNA and have high biological activity (Karapetian A.T. et al., 1996).

The comparison of the theory with experiment has revealed that $\mathrm{EtBr}$ and Actinomycin $\mathrm{D}$ (AMD) bind with double-stranded (-ds) and single-stranded (-ss) DNA in several types (multimodal ligands) and the number of types of interaction depends on ionic strength of solution (Karapetian A.T. et al., 1996).

The present work is devoted to experimental study of features of interaction of multimodal ligands with DNA depending on ligand concentration and ionic strength of solution.

\section{Materials and Methods}

\section{Materials}

Ultrapure Calf Thymus DNA and EtBr (Serva, Germany) were used in this work. All preparations were used without additional purification. Concentration of used preparations were determined by absorption spectroscopy, using the values of molar extinction for calf thymus DNA $-\varepsilon_{260}=6400 \mathrm{M}^{-1} \mathrm{~cm}^{-1}$, and $\mathrm{EtBr}-\varepsilon_{480}=$ $5600 \mathrm{M}^{-1} \mathrm{~cm}^{-1}$, respectively (Sidorenko N.V. and Kosaganov Yu.N, 1973). The research was carried out in solutions $0.01 ; 0.05 ; 0.1 \times$ SSC $(1 \times$ SSC contains $0.15 \mathrm{M} \mathrm{NaCl}$ and $0.015 \mathrm{M} \mathrm{Na}$-citrat), $10^{-5} \mathrm{M}$ EDTA. The ionic strength was changed in an interval $2.0 \times 10^{-3} \leq \mu_{\mathrm{Na}+} \leq 2.0 \mathrm{x}$ $10^{-2} \mathrm{M}$.

\section{Spectrophotometric measurements}

Spectrophotometric measurements were carried out on spectrophotometer Pye Unicam-SP8-100 (England). The melting of DNA and its complexes with EtBr carried out in hermetic closed quartz cuvetts, placed in a thermostatic cell of the spectrophotometer. The heating was carried out with the help of the program device with the speed of $0.25^{\circ} \mathrm{C} / \mathrm{min}$. The absorption $\left(\mathrm{A}_{260}\right)$ was deduced on programmed microcalculator HP 97S I/0.

$T_{m}$ and $\Delta T$ were determined as it was described in the previous work (Karapetian A.T. et al., 1990). In order to prevent probable statistical errors melting of complexes DNA-EtBr was carried out simultaneously with melting of DNA itself. For exception of errors caused on light cuttering owing to formation of aggregates, in all experiments the ratio of $A_{320} / A_{260}$ was controlled not to exceed permissible values.

\section{Results and Discussion}

The developments of novel drugs for DNA-mediated reactions are closely related to the sequence-specificity of ligands with DNA (Chaires J.B. et al., 1996). 
Understanding the nature of association between the interacting ligands to DNA is essential when the new agents for DNA binding are investigated for their target (Chaires J.B. et al., 1996). Intercalation, in which a planar ligand molecule is inserted between adjacent base pairs, results in the lengthening, stiffening, and unwinding of DNA helix. Due to intercalation, the planar chromophores are in close contact with the DNA base pairs, and are oriented roughly perpendicular to the DNA helix axis (Suh D., 2000). Moreover, it was shown earlier, that EtBr, AMD are showing multimodality at their interaction with DNA (Karapetian A.T. et al., 1996). Thus, in comparison of melting curves of DNA itself, with the melting curves of named ligand complexes are shift in the range of high temperatures, i.e. at the certain concentration they are stabilizing of double stranded DNA structure (Karapetian et al., 1972, Tishchenko E.I. et al., 1996). Theoretically and experimentally, it has been shown that the dependence of $\delta \Delta \mathrm{T}$ widening on a ratio of concentration $r_{b}=2 D / P$ (where $D$ is the total concentration of ligand in a solution, and $P$ is the phosphate groups concentration of DNA) has the bellshaped form. The value of $\Delta \mathrm{T}$ at first grows and, passing through slow expressed maximum, decreases, and at observance of the certain conditions (see work Karapetian A.T. et al., 1998) $\Delta \mathrm{T}$ of a complex becomes equal to $\Delta T_{0}$ of DNA itself. It occurs when the total concentration of the ligand bound with both forms of DNA (i.e. native and denatured) are equal to each other at the transition point $(\vartheta=0.5)$.

The curve describing a change of the melting temperature $\delta T_{m}\left(\delta T_{m}=T_{m}-T_{o}\right.$, where $T_{m}$ is melting temperature of complexes, and $T_{0}$ is the one of DNA itself) on $r_{b}$ rises linearly. At the further increasing of ligand concentration leads to $\Delta T$ grows, while $T_{m}$ is decreasing. Analysis of experimental data has shown that at low ionic strength the stabilizing effects of $\mathrm{EtBr}$ and $\mathrm{AMD}$ on a double strand DNA are differed (Karapetian A.T., 1998).

On Figure 1 the theoretical curve dependencies of $\delta\left(\Delta T / T_{m}{ }^{2}\right)$ on $r_{b}$ are given (see Karapetian et al., 1996). As it is shown from given figure (curve 1), the dependence maximum of $\delta\left(\Delta T / \mathrm{T}_{\mathrm{m}}{ }^{2}\right)$ value against $\mathrm{r}_{\mathrm{b}}$ in a case of $\mathrm{EtBr}$ is roughly rising at the ionic strength equal to 2.0 $\times 10^{-3} \mathrm{M} \mathrm{Na}^{+}$, while in the case of AMD at the same ionic strength, as well as for AMD and $\mathrm{EtBr}$ at the $2.0 \times$ $10^{-2} \mathrm{M} \mathrm{Na}^{+}$the maximum practically remains invariable (curves 2; 3). Such results of the theory help to choose corresponding parameters, where strong and weak ways of binding with DNA are taken into account.

Apparently, it is caused by weak electrostatic interaction of the positively charged groups of $\mathrm{EtBr}$ with negatively charged phosphate groups of DNA, which does not occur in the case of AMD. The evidence of such assumption can indicate the experimental fact that as the ionic strength of a solution increases up to $2.0 \times$ $10^{-2} \mathrm{M} \mathrm{Na}^{+}$the phosphate groups are screened by the

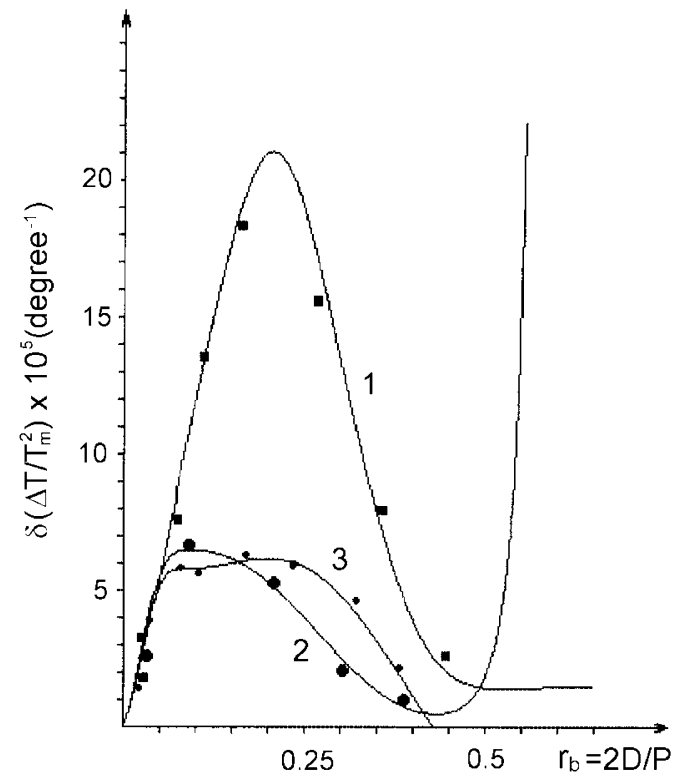

Figure 1. Theoretical curves of dependences of $\delta\left(\Delta \mathrm{T} / \mathrm{T}_{\mathrm{m}}{ }^{2}\right) \times 10^{5}$ on ligand concentration $\left(r_{b}=2 D / P\right)$, designed for certain values of parameters of the theory, on which the experimental points are given: $1-\mathrm{EtBr}$ at $\mu_{\mathrm{Na}^{+}}=$ $2.2 \times 10^{-3} \mathrm{M}, 2-\mathrm{AMD}$ at $\mu_{\mathrm{Na}^{+}}=2.2 \times 10^{-3} \mathrm{M}, 3-\mathrm{EtBr}$ and $\mathrm{AMD}$ at $\mu_{\mathrm{Na}^{+}}$ $=2.2 \times 10^{-2} \mathrm{M}$.

shielded $\mathrm{Na}^{+}$, ions resulting in the prevention of the electrostatic binding of EtBr with DNA, and the character of $\delta\left(\Delta T / T_{m}{ }^{2}\right)$ dependence on $\mathrm{EtBr}$ concentration becomes the same, as well as for AMD. The further increasing of ionic strength up to normal physiological conditions $\left(\mu=10^{-1} \mathrm{M} \mathrm{Na}^{+}\right)$does not influence on this dependence.

For a substantiation of above mention we carried out an experimental research of helix-coil transition of DNAEtBr complexes in an interval of change of ionic strength equal to $2.0 \times 10^{-3} \leq \mu_{\mathrm{Na}+} \leq 2.0 \times 10^{-2} \mathrm{M}$ at change of ligand concentration in an interval of $0.25 \leq r_{b} \leq 0.60$.

On Figure 2 are given the melting curves of complexes of DNA- EtBr at $\mu_{\mathrm{Na}+}=2.0 \times 10^{-2} \mathrm{M}$, which are shifted in the range of high temperatures at increasing of $\mathrm{EtBr}$ concentration $r_{b}$ (curves 1-3), while the width of the melting interval decreases and for curve $3, \Delta T$ is the same, as for the DNA itself (data not shown). The further increasing of the ligand concentration results in decreasing of the melting temperature (curve 4), while $\Delta \mathrm{T}$ of a complex is increased.

On Figure 3 (A and $B$ ) the curves of $\delta T_{m}$ and $\delta(\Delta T)$ dependencies on ligand concentration received from melting curves at the basis of transition curves at ionic strength of $2.0 \times 10^{-3} \leq \mu_{\mathrm{Na}+} \leq 2.0 \times 10^{-2} \mathrm{M}$.

As shown in Figure $3 \mathrm{~A}$, the dependence of $\delta(\Delta \mathrm{T})$ on $r_{b}$ gradually decreases and at certain high concentrations of ligand is equal to zero (curves 1-3), i.e. the melting intervals of DNA-EtBr complex and DNA itself become equal. 


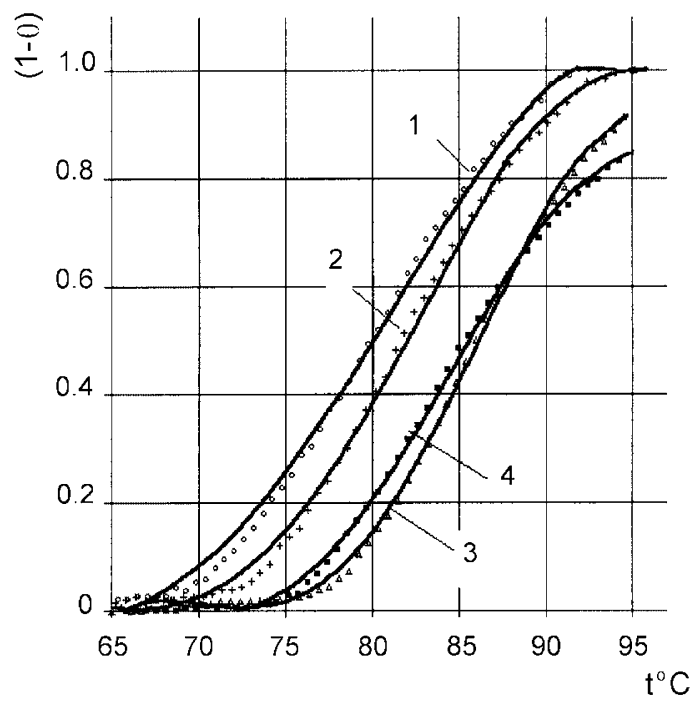

Figure 2. Melting curves of complexes of DNA-EtBr at various c: 1-0.33; 2$0.4 ; 3-0.5 ; 4-0.51$. DNA Concentration-6.6 $\times 10^{-5} \mathrm{M} ; \mathrm{pH} 7.0 ; \mu_{\mathrm{Na}^{+}}=2.2 \times$ $10^{-2} \mathrm{M}$.
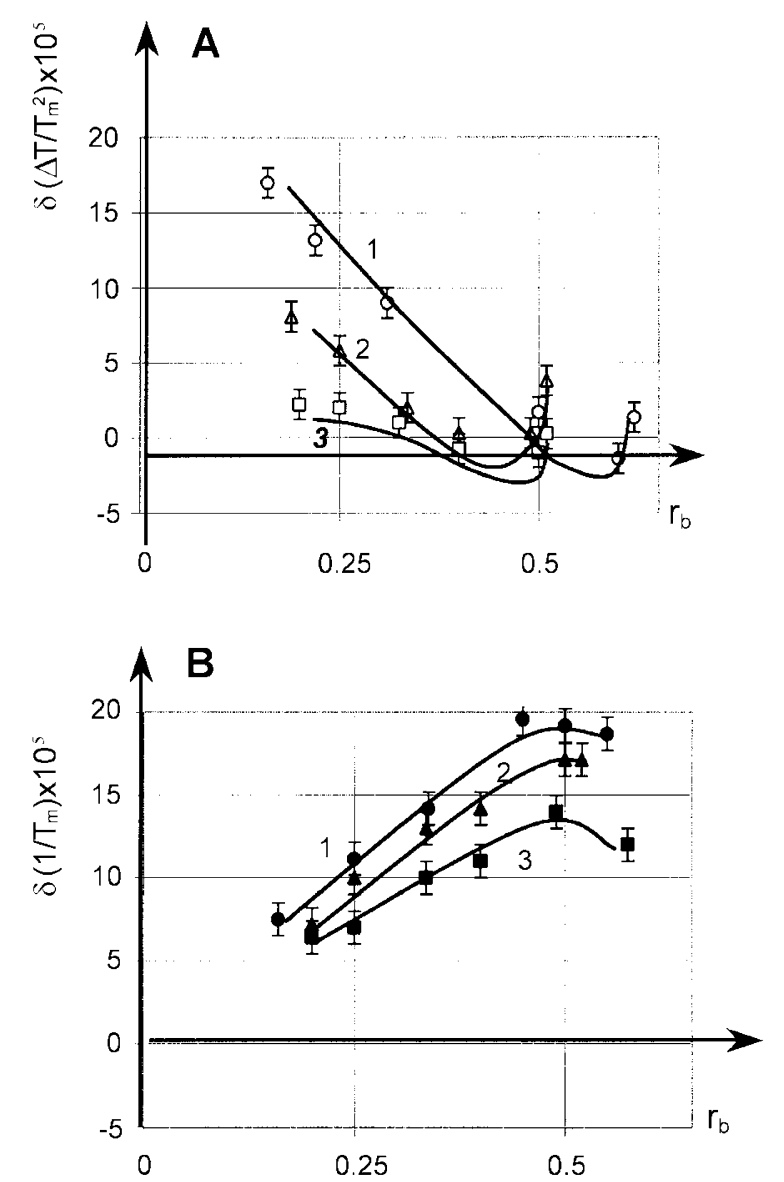

Figure 3. Experimental curves of dependencies of $\delta\left(\Delta \mathrm{T} / \mathrm{T}_{\mathrm{m}}{ }^{2}\right) \times 10^{5}(\mathrm{~A})$ and $\delta(1 / \mathrm{Tm}) \times 10^{5}(\mathrm{~B})$ on $\mathrm{c}\left(\mathrm{r}_{\mathrm{b}}\right)$, obtained from melting curves of complexes of DNA-EtBr at ionic strength $\mu_{\mathrm{Na}^{+}}=2.2 \times 10^{-3} \mathrm{M}$ (curve 1), $\mu_{\mathrm{Na}^{+}}=1.0 \times$ $10^{-2} \mathrm{M}$ (curve 2), $\mu_{\mathrm{Na}^{+}}=2.2 \times 10^{-2} \mathrm{M}$ (curve 3), $\mathrm{pH}=7.0$. The average square deviation mistakes are shown.
As the ionic strength of a solution decreases, the dependence of $\delta(\Delta T)$ on $r_{b}$ becomes equal to zero at a higher ligand concentration, that, apparently, is caused by existing more than one weak way of binding. This way of interaction, probably, has an electrostatic origin, as at high ionic strength there is a shielding of phosphate groups of DNA, because the positively charged groups of $\mathrm{EtBr}$ do not interact with negatively charged phosphate groups of DNA and for this reason the saturation of binding sites on ds-DNA occurs at smaller ligand concentrations.

The further increasing of ligand concentration results in increasing of melting width of a complexes, i.e. the stabilizing of ds-DNA turnout in a destabilizing, because in a point $\delta\left(\Delta T / \mathrm{T}_{\mathrm{m}}{ }^{2}\right)=0$ the double strands sites of DNA are saturated by ligand, while the ss-sites still remain into not saturated and ligand begins to interact with these sites.

On Figure 3B it is shown, that the dependence of $\delta \mathrm{T}_{\mathrm{m}}$ on $r_{b}$ linearly grows up to the certain value of $r_{b}\left(r_{b} \cong\right.$ 0.5 ), and at higher meanings of $r_{b}$ this dependence deviates from linearity (curves 1-3). On Figure $3 B$ it is also shown, that the curve sloping of dependencies of the $\delta T_{m}$ on $r_{b}$ decreases with rising of the ionic strength of a solution. It is indirect confirmation that at low ionic strength $\mathrm{EtBr}$ has an additional, weak way of binding with DNA. Probably, at low ionic strength there is no hindrance for realization of another (others) weaker (weak) in comparison with intercalation and semi-intercalation ways of binding. These results within the limits of an error bar of experiment are in good agreement with the literature data (Wadkins et al., 1996, Wadkins R.M., and Jovin T.M., 1991, Vardevanyan et al., 2000).

For the first time we have obtained experimental results which confirmed the above mentioned theoretical conclusions that the number of ways of binding EtBr with DNA depends on ionic strength of a solution and at saturation of binding sites of ligand on ds-DNA, when still there are free sites on Ss-DNA, the stabilizer of a double helix transformed into the destabilizer.

The similar researches were carried out also with complexes of EtBr with poly[d(A-T)]-poly[d(A-T)], Sdphage and $\mathrm{Cl}$. perfringenes DNA. These data are in good agreement with results, obtained for calf thymus DNA (the experimental data are not mentioned). These results specify that the weak way of $\mathrm{EtBr}$ binding with DNA, which takes place at low ionic strength $(\mu=$ $\left.2.0 \times 10^{-3} \mathrm{M} \mathrm{Na}^{+}\right)$and high $r_{b}\left(r_{b} \geq 0.5\right)$, does not depend on a type of base and are the other evidence of theoretical conclusions of works (Vardevanyan et al., 2000).

Up to now the influence of drug concentration binding with DNA has not been studied yet, bat it is well known that these compounds interact with DNA generally in one way, by inhibition of replication and transcription processes by stabilizing. For a successful solution 
of this problem, results obtained in this paper, where it is shown the existention class of ligands which are interacted with DNA multimodally can be very useful.

Obtained results reveal that drugs or dyes are preferentially binding with ds-DNA depending on their concentration and can stabilize as well as destabilize the double helix of DNA. Therefore these ligands can be successfully used as chemotherapeutic compounds, but also leads to undesirable consequences. In this point of view the further investigations of influence of anticancer drugs depending on concentration are important for understanding of their undesirable action mechanisms.

\section{Acknowledgments}

The authors thank Prof.Valery Ivanov and Prof. Olga Borisova for discussion of results and Prof. Dmitry Lando for kindly giving the high purity Calf Thymus DNA.

\section{References}

Antonini I, Polucci P, Jenkins TC, Kelland LR, Menta E, Pescalli N, Stefanska B, Mazerski J, Martelli S. 1-[( $\omega-$ aminoalkyl)amino]-4-[N-( $\omega$-aminoalkyl)carbamoyl]-9-oxo-9,10dihydroacridines as intercalating cytotoxic agents: synthesis, DNA binding, and biological evaluation. J Medicinal Chem 1997; 40:3749-55

Chaires JB. Dissecting the free energy of drug binding to DNA. Anti-Cancer Drug. Des. 1996;11:569-80

Chaires JB. Energetics of drug-DNA interactions. Biopolymers 1998;44:201-15

Karapetian AT. "Tie calorimetry": Teory and Experiment. Mol. Biol. (Russia) 1991;25:325-36

Karapetian AT, Mehrabian NM, Terzikian GA, Antonian AP, Vardevanian PO, Frank-Kamenetskii MD. Theoretical and experimental study of conformational transitions of complexes of DNA with ligands having several types of binding sites on different forms of DNA. Structure, motion, interaction and expression of biological macromolecules. Adenine Press, 1998;259-66

Karapetian AT, Mehrabian NM, Terzikian GA, Vardevanian PO, Antonian AP, Borisova OF, Frank-Kamenetskii MD. Theoretical treatment of melting of complexes of DNA with ligands having several types of binding sites on helical and single-stranded DNA. J Biomol Struct Dyn 1996;14:275-83

Karapetian AT, Permogorov VI, Frank-Kamenetskii MD, Lazurkin YuS. Thermodynamic investigations of complexes of DNA with drugs. Molecular biology (Rus) 1972;867-74

Karapetian AT, Vardevanian PO, Frank-Kamenetskii MD. Enthalpy of helix-coil transition of DNA: Dependence on $\mathrm{Na}^{+}$ concentration and GC-content. J Biomol Structure \& Dynamics 1990;8:131-38

Lane AN, Jenkins TC. Thermodynamics of nucleic acids and their interactions with ligands. Quarterly Reviews of Biophysics 2000;33:255-306

Sidorenko NV, Kosaganov YuN. Physical and chemical investigations of interaction of DNA with RNAase A. In: The conformational changes of biopolymers in solution. M. 1973

Suh D. Environments of ethidium binding to allosteric DNA: II. Accessibility, mobility and mode of binding. Exp Mol Med 2000;32:204-9

Tishchenko El, Karapetian AT, Borisova OF. The heterogen complexes of EtBr and their role in stabilizing of $(\mathrm{dA})_{n}-(\mathrm{dT})_{\mathrm{n}}$. Molecular biology (Rus) 1996;30:1370-77

Vardevanyan PO, Antonyan AP, Manukyan GAT, Karapetian AT, Shchelkina AK, Borisova OF. Binding of $\mathrm{EtBr}$ with native and denaturated poly(dA)poly(dT). Molecular biology (Rus) 2000;34:310-15

Wadkins RM, Jares-Erijman AE, Klement R, Rudiger A, Jovin TM. Actinomicin D Binding to Single-stranded DNA: Sequence specifity and hemi-intercalation model from fluorescence and ${ }^{1}$ H NMR spectroscopy. J Mol Biol 1996;53-68

Wadkins RM, Jovin TM. Actinomycin D and 7-aminoactinomycin D binding to single-stranded DNA. Biochem 1991;30: 9469-78 